\title{
ANALYSIS AND EXPERIMENTAL INVESTIGATION TO MITIGATE MECHANICAL VIBRATION AND ACOUSTIC NOISE IN DIRECT TORQUE CONTROLLER FED PMSM
}

\author{
R Sathya $^{1}$, A Sivaprakasam ${ }^{2}$, T Manigandan ${ }^{3}$ \\ ${ }^{I}$ P.G Scholar, Dept. of EEE, Kongu Engineering College, Tamil Nadu, India \\ ${ }^{2}$ Assistant Professor (Selection Grade), Dept. of EEE, Kongu Engineering College, Tamil Nadu, India \\ ${ }^{3}$ Principal, P.A. College of Engineering and Technology, Tamil Nadu, India
}

\begin{abstract}
The permanent magnet synchronous motor (PMSM) is receiving wide attention for industry application due to their high reliability, high power, high torque density and high efficiency. Recently, for application requiring high dynamic performance, direct torque control (DTC) is employed. Compared to other technique, DTC directly manipulates the final output voltage vector without the need of inner current loop and hence eliminate the inherent time delay. In spite of the merits, it had some disadvantages like large torque ripple and large acoustic noise among others. The mechanical vibration and acoustic noise are directly related to the large torque ripple. In existing, DTC fed PMSM uses the method of effective voltage vector combinations to reduce the torque ripple and thereby reduce the mechanical vibration and acoustic noise. In this proposed work, the analysis of mechanical vibration and acoustic noise is analyzed in both simulation and experimentally for various speeds and load changes. This analysis is done by using the Lab VIEW graphical programming language platform, which provides an efficient and accurate result.
\end{abstract}

Keywords: Acoustic noise, Frequency domain analysis, Direct Torque Control (DTC), Mechanical vibration, Permanent magnet synchronous motor (PMSM), Time domain analysis

\section{INTRODUCTION}

Permanent magnet synchronous motor (PMSM) has found wide applications due to their high power density, high efficiency, ease of control, high torque to inertia and high reliability. For application requiring high dynamic performance, current vector control is often employed. Recently alternative high performance control technique named Direct Torque Control (DTC) which is initially developed for induction motor drives, has also been investigated in PMSM. In spite of the merits in DTC, it also has some disadvantages like large torque ripple, variable switching frequency and because of this large torque ripple, the mechanical vibration and acoustic noise occur in the motor.

The mechanical vibration is a frequent occurrence in the working process of equipment in the mechanical engineering field. Vibration can not only produce noise to harm human health but also has the energy, which can affect the equipment life and operation stability. The vibration is negative even harmful, the influence of vibration can be reduced or eliminated using vibration test analysis. In some cases, vibration can also be used, for example vibration transmission and vibrating screen etc. At this time the purpose of vibration test is how to produce the desired vibration and impact effect. Abundant information about state change and fault feature of equipment are included in vibration signal. So the measure and analysis of it are necessary for both eliminating and using mechanical vibration. The traditional vibration test system composed of independent measurement instruments, and single function, poor reliability testing results and high cost all its disadvantages. Therefore, it is greatly restricted in practical application. With the development of computer technology, virtual instrument which is different from traditional instruments appeared. It realized the concept of "software is instrument". Lab VIEW is a virtual instrument software development tool based on Graphics Language. It has a function of data analysis, signal occurrence, processing and input/output control. This program is called VI which is programmed by Lab VIEW development platform. A complete VI consists of three parts: the front panel of program, diagram program and icon/connector.

This paper systematically analyzed the basic principle of the PMSM DTC and the related torque ripple minimization technique are highlighted in section II and in section III the proposed scheme were discussed and in section IV the simulation and results were discussed and finally the section $\mathrm{V}$ is concluded. 


\section{DTC OF PMSM DRIVES}

One of the challenges posted for the high performance DTC is to acquire an accurate representation of the instantaneous electromagnetic torque. Direct torque control is an optimized AC variable frequency drive control principle where inverter switching directly controls the motor variables flux and torque. For that we require only knowledge about the stator voltage and resistance. The basic six sectors based DTC

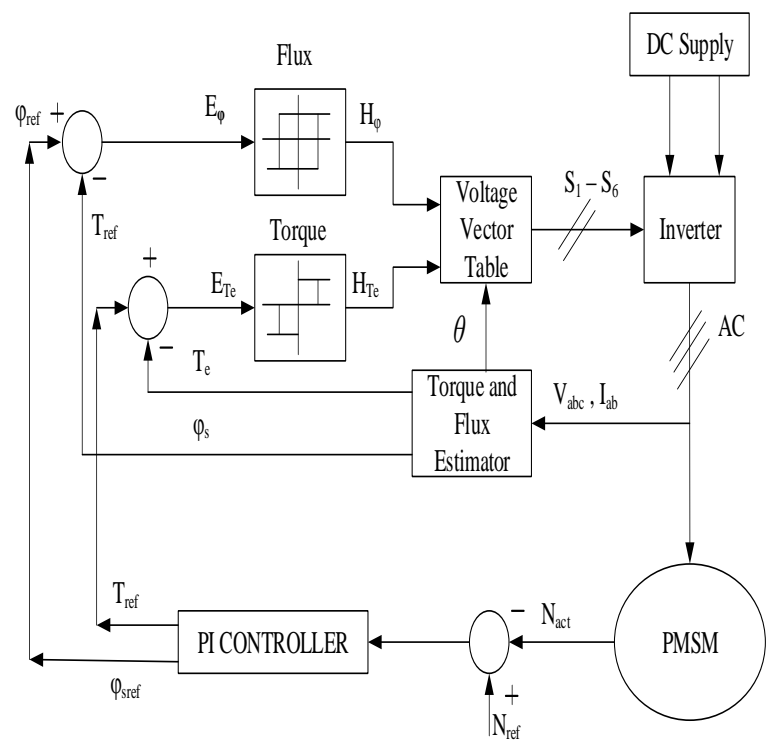

Fig- 1: Schematic of a direct torque controlled PMSM drive

The block diagram is given in the Fig- 1. The stator voltage and resistance are measured from that the actual flux and torque are estimated that is compared with the reference flux and torque respectively. The error is given to the hysteresis comparator depending on the output levels of this hysteresis comparator, the is due to voltage vector is selected from the switching table and applied to the voltage source inverter in order to get the reference torque.

\subsection{Six Sector Concept}

The entire section is divided into 6 sectors that by having each section as 60 degree which is shown in the below figure. Depending upon the real and reference value the corresponding switching vector is selected in the corresponding section. The switching table for the 6 sector based direct torque control is as shown in Fig- 2. Here we implemented the 3 level torque hysteresis and two level flux hysteresis controllers which clearly understand from the given below table and here we designed 8 voltage vectors combinations for the 6 sector based design.

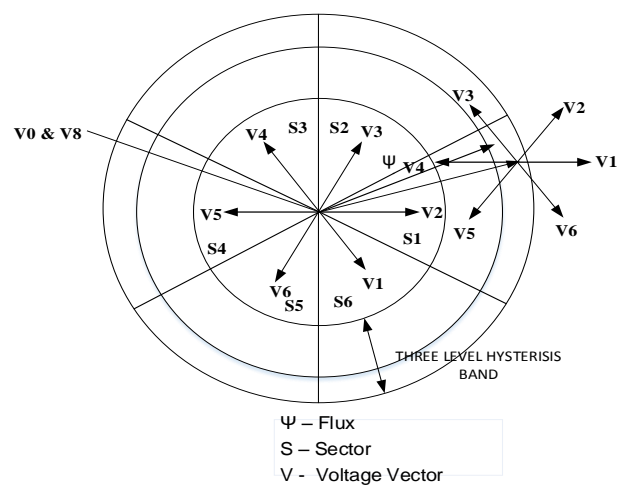

Fig -2: Six Sector Concept

The V0 and V7 are used as a zero vector that is if we select these vectors there is no change in the torque and flux if we choose the others we will get the corresponding torque and flux deflection. In each region, two adjacent voltage the vectors, which give the least switching frequency, are preferred to increase or decrease the amplitude of stator flux linkage respectively.

Table- 1: Switching Table for Six Sectors with 8 Voltage vectors

\begin{tabular}{|c|l|l|l|l|l|l|l|}
\hline \multirow{2}{*}{$\mathrm{H}_{\psi}$} & $\begin{array}{l}\mathrm{H} \\
\mathrm{Te}\end{array}$ & $\begin{array}{l}\theta \\
(1)\end{array}$ & $\begin{array}{c}\theta \\
(2)\end{array}$ & $\begin{array}{c}\theta \\
(3)\end{array}$ & $\begin{array}{c}\theta \\
(4)\end{array}$ & $\begin{array}{c}\theta \\
(5)\end{array}$ & $\begin{array}{l}\theta \\
(6)\end{array}$ \\
\hline \multirow{2}{*}{1} & 1 & $\mathrm{~V} 2$ & $\mathrm{~V} 3$ & $\mathrm{~V} 4$ & $\mathrm{~V} 5$ & $\mathrm{~V} 6$ & $\mathrm{~V} 1$ \\
\cline { 2 - 8 } & 0 & $\mathrm{~V} 0$ & $\mathrm{~V} 7$ & $\mathrm{~V} 0$ & $\mathrm{~V} 7$ & $\mathrm{~V} 0$ & $\mathrm{~V} 7$ \\
\cline { 2 - 8 } & -1 & $\mathrm{~V} 6$ & $\mathrm{~V} 1$ & $\mathrm{~V} 2$ & $\mathrm{~V} 3$ & $\mathrm{~V} 4$ & $\mathrm{~V} 5$ \\
\hline \multirow{2}{*}{-1} & 1 & $\mathrm{~V} 3$ & $\mathrm{~V} 4$ & $\mathrm{~V} 5$ & $\mathrm{~V} 6$ & $\mathrm{~V} 1$ & $\mathrm{~V} 2$ \\
\cline { 2 - 8 } & 0 & $\mathrm{~V} 7$ & $\mathrm{~V} 0$ & $\mathrm{~V} 7$ & $\mathrm{~V} 0$ & $\mathrm{~V} 7$ & $\mathrm{~V} 0$ \\
\cline { 2 - 8 } & -1 & $\mathrm{~V} 5$ & $\mathrm{~V} 6$ & $\mathrm{~V} 1$ & $\mathrm{~V} 2$ & $\mathrm{~V} 3$ & $\mathrm{~V} 4$ \\
\hline
\end{tabular}

For example, in Fig. 2, vectors $V_{2}$ and $V_{3}$ are selected to increase and decrease the amplitude of stator flux linkage when $\Psi$ s in region one and rotating in counter-clockwise. In this way, $\Psi_{\mathrm{s}}$ can be controlled at the required value by selecting the proper voltage vectors from the table 1 we can control the flux linkage through that we can able to control the torque.

Fig- 3 shows how the voltage vectors are selected for keeping $\Psi_{\mathrm{s}}$ within a hysteresis band when $\Psi_{\mathrm{s}}$ is rotating in the counter clockwise direction 


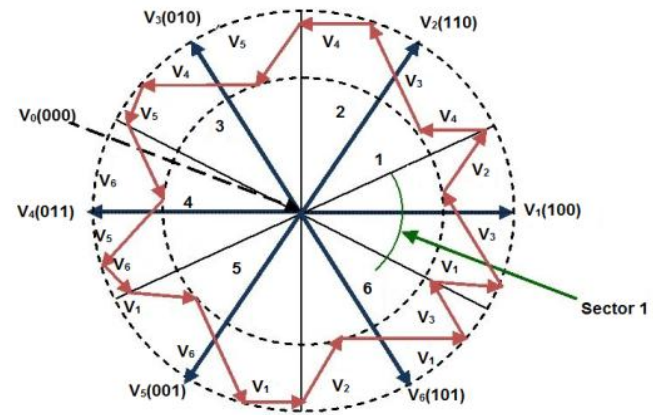

Fig- 3: Control of the Stator Flux Linkage

\section{PROPOSED SCHEME}

\subsection{Block Diagram for Proposed Scheme}

The feedback torque is calculated from the PMSM machine terminal voltage and currents. The estimated torque is compared with reference torque and by sampling time $(\mathrm{N})$, by the way the torque ripple is calculated, using the formula (1),

$$
T_{\text {ripple }}=\sqrt{\frac{1}{N} \sum_{i=1}^{N}\left(T_{e}(i)-T_{a v}\right)^{2}}
$$

Where,

$$
\begin{aligned}
& \mathrm{T}_{\text {ripple}}=\text { Torque ripple } \\
& \text { Te=actual value } \\
& \text { Tav=Reference value } \\
& \mathrm{N}=\text { sampling period }
\end{aligned}
$$

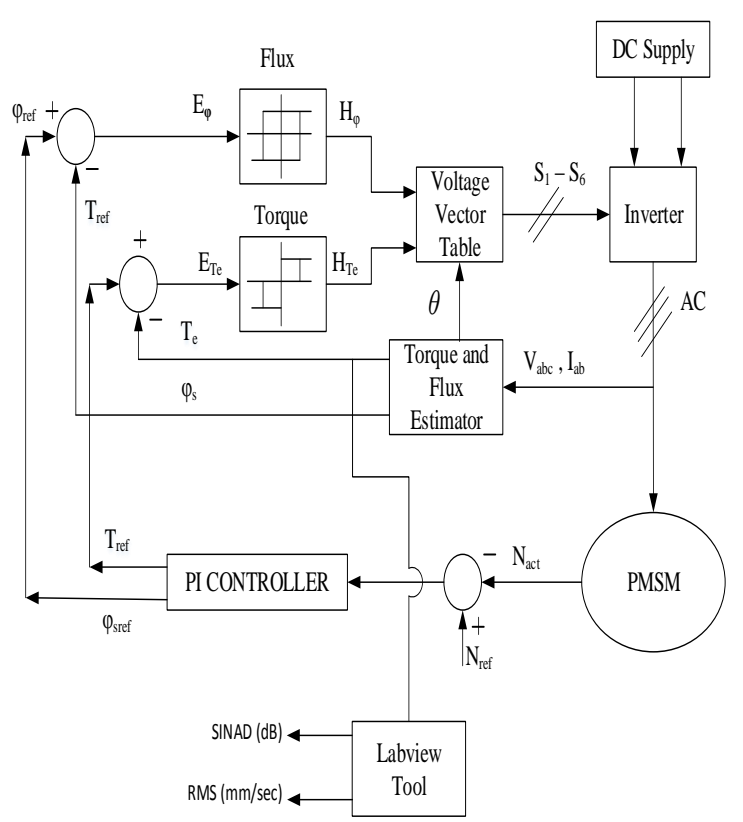

Fig- 4: Schematic of a direct torque controlled PMSM drive
And here, the torque ripple is directly related to the mechanical vibration and acoustic noise is one of the relations which reduces the vibration and noise which occurred in the DTC fed PMSM. The velocity is a vibration amplitude parameter is a rate of change of displacement of vibration signal. It is the most common machine vibration measurement. And also it is measured in $\mathrm{mm} / \mathrm{Sec}$ (True RMS value). This parameter is sensitive to the vibration frequencies ranging from 600 to 60,000 CPM. By using the Lab VIEW software for analyzing the mechanical vibration and acoustic noise in two measurement process. One is time domain measurement, this analysis gives the real time signal and extract the signal characteristics like the value of amplitude. Another one is a frequency domain measurement, the various information like amplitude, phase, power spectrum, Fast Fourier Transform (FFT) are obtained from the by this measurement. This analysis gives more information about the signal and signal through which is generated.

\section{SIMULATION AND RESULTS}

In time domain measurement it gives the amplitude of the signal at that instant of time during which the instant it was sampled. Using single integration the acceleration of vibration signal, the analysis of vibration signal is performed. This vibration signal is measured in true Root Mean Square (RMS) value. In Distortion measurement, which measure the distorted noise signal associated in the torque waveform.

\subsection{Results for Time Domain Measurement}

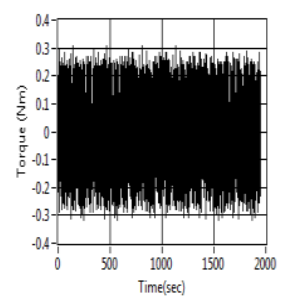

(a)

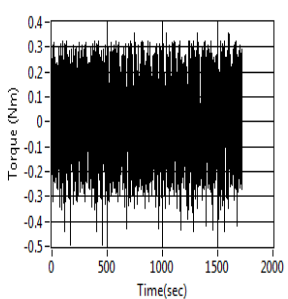

(b)

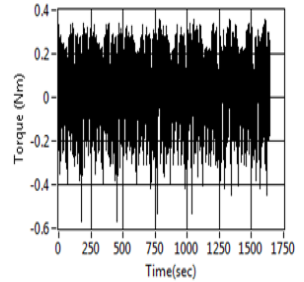

(c)
Fig- 5: Response of a torque waveform of DTC fed PMSM for a speed of $1000 \mathrm{rpm}$ (a) Torque waveform for $1000 \mathrm{rpm}$ at no load condition (b) Torque waveform for $1000 \mathrm{rpm}$ at $2 \mathrm{Nm}$ load condition (c) Torque waveform for $1000 \mathrm{rpm}$ at $3 \mathrm{Nm}$ load

Table- 2: Quantitative Analysis Table for Time Domain Measurement

\begin{tabular}{|c|c|c|c|}
\hline LOAD & $\begin{array}{l}\text { SPEED } \\
(\mathrm{RPM})\end{array}$ & $\begin{array}{l}\text { RMS } \\
(\mathrm{mm} / \mathrm{sec}) \text { for } \\
\text { vibration level }\end{array}$ & $\begin{array}{l}\text { SINAD } \\
(\mathrm{dB})\end{array}$ \\
\hline \multirow{2}{*}{ NO } & 200 & 0.1959 & -0.1574 \\
\cline { 2 - 4 } & 500 & 0.1996 & 1.6270 \\
\hline
\end{tabular}




\begin{tabular}{|c|c|c|c|}
\hline \multirow{3}{*}{ LOAD } & 700 & 0.1945 & 1.0956 \\
\cline { 2 - 4 } & 1000 & 0.1920 & 0.8804 \\
\hline \multirow{3}{*}{$2 \mathrm{Nm}$} & 200 & 0.1975 & 0.7929 \\
\cline { 2 - 4 } & 500 & 0.1944 & 0.9137 \\
\cline { 2 - 4 } & 700 & 0.1927 & 0.9563 \\
\cline { 2 - 4 } & 1000 & 0.1983 & 0.5179 \\
\hline \multirow{4}{*}{$3 \mathrm{Nm}$} & 200 & 0.1954 & 1.1458 \\
\cline { 2 - 4 } & 500 & 0.1988 & 0.9014 \\
\cline { 2 - 4 } & 700 & 0.1994 & 0.1784 \\
\cline { 2 - 4 } & 1000 & 0.1997 & 0.8715 \\
\hline
\end{tabular}

In time domain measurement table- 2. Shows the analysis of vibration level in term of velocity in the RMS $(\mathrm{mm} / \mathrm{sec})$ and the acoustic noise in terms of Signal in Noise and Distortion (SINAD) (dB) for various speeds and load changes. Velocity is the rate of change of displacement of vibration signal that would be in true RMS value. As per the ISO 2372 guidelines for vibration measurement, it should be in the acceptance ranges for all no load, load conditions of $2 \mathrm{Nm}$ and $3 \mathrm{Nm}$. From the analyzed value of time domain measurement, the low value for mechanical vibration and acoustic noise at load, no load condition. The vibration level at a speed of $1000 \mathrm{rpm}$ for no load condition is $0.1920 \mathrm{~mm} / \mathrm{sec}$ and a $0.1784 \mathrm{~dB}$ at a speed of $700 \mathrm{rpm}$ in $3 \mathrm{Nm}$.

In simulation model for frequency domain measurement is shown in Fig- 7, the velocity which is in time domain is converted into frequency domain using FFT algorithm. The frequency domain of vibration is presented in power spectrum.

\subsection{Results for Frequency domain measurement}

Table- 3: Quantitative Analysis Table for Frequency Domain Measurement

\begin{tabular}{|c|c|c|c|c|c|}
\hline LOAD & $\begin{array}{l}\text { SPEE } \\
\text { D } \\
\text { (rpm) }\end{array}$ & $\begin{array}{l}\text { AVERA } \\
\text { GE } \\
\text { NOISE } \\
\text { LEVEL } \\
\text { (dB) }\end{array}$ & $\begin{array}{l}\text { TOTA } \\
\text { L } \\
\text { NOISE } \\
\text { LEVE } \\
\text { L (dB) }\end{array}$ & $\begin{array}{l}\text { SINA } \\
D(d B)\end{array}$ & $\begin{array}{l}\text { SNR } \\
(\mathrm{dB})\end{array}$ \\
\hline \multirow{4}{*}{$\begin{array}{l}\text { NO } \\
\text { LOAD }\end{array}$} & 200 & 0.2761 & 0.0381 & 6.8523 & 3.3960 \\
\hline & 500 & 0.2843 & 0.0404 & 6.0554 & 2.2804 \\
\hline & 700 & 0.2763 & 0.0382 & 6.3997 & 4.6415 \\
\hline & 1000 & 0.2706 & 0.0366 & 6.0718 & 1.4062 \\
\hline \multirow{4}{*}{$2 \mathrm{Nm}$} & 200 & 0.2762 & 0.0382 & 5.5923 & 3.4752 \\
\hline & 500 & 0.2743 & 0.0376 & 3.9433 & 0.3080 \\
\hline & 700 & 0.2722 & 0.0370 & 4.9052 & 2.8226 \\
\hline & 1000 & 0.2775 & 0.0385 & 2.3769 & -2.9023 \\
\hline \multirow{4}{*}{$3 \mathrm{Nm}$} & 200 & 0.2725 & 0.0371 & 3.9960 & -1.0291 \\
\hline & 500 & 0.2837 & 0.0403 & 3.1809 & -1.2748 \\
\hline & 700 & 0.2820 & 0.0398 & 3.0925 & -3.2256 \\
\hline & 1000 & 0.2847 & 0.0406 & 3.1296 & -1.3974 \\
\hline
\end{tabular}

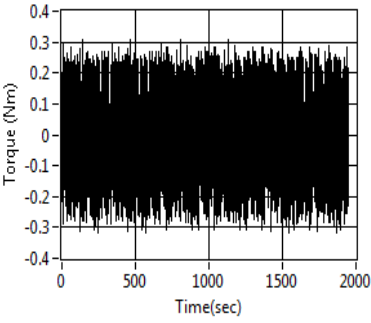

(a)

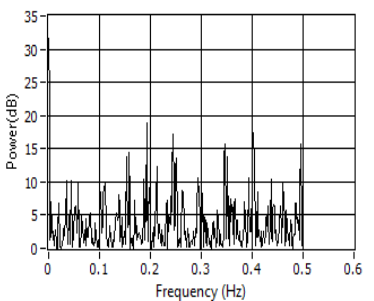

(c)

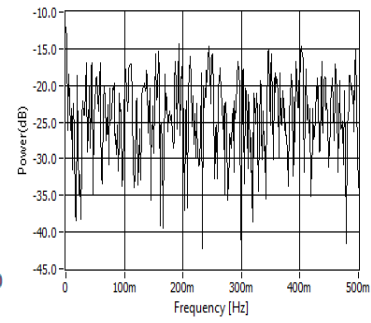

(b)

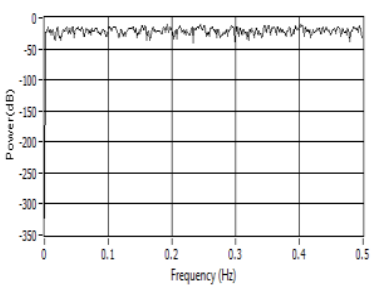

(d)
Fig- 8: Measured waveform for vibration and noise for DTC fed PMSM at a speed of $1000 \mathrm{rpm}$ at no load condition (a) Torque response waveform (b) Power spectrum waveform (c) Noise measurement waveform (d) Tone measurement waveform.

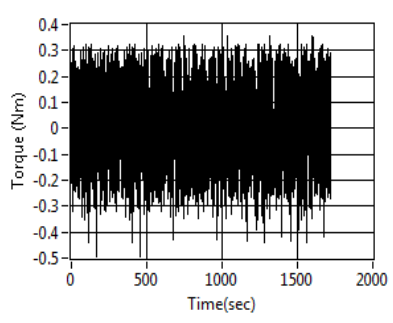

(a)

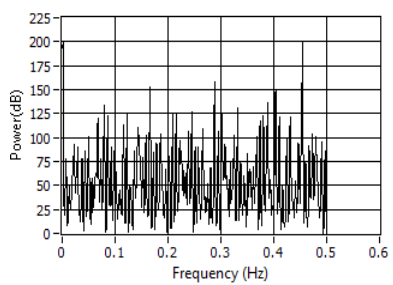

(c)

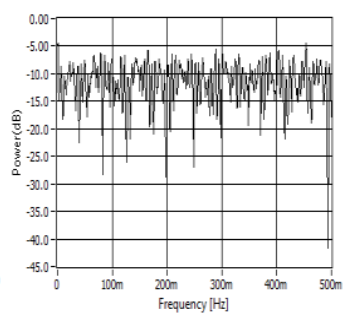

(b)

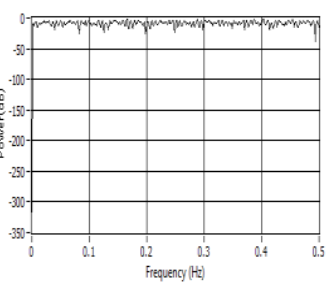

(d)
Fig- 9: Measured waveform for vibration and noise for DTC fed PMSM at a speed of $1000 \mathrm{rpm}$ at $2 \mathrm{Nm}$ load condition (a) Torque response waveform (b) Power spectrum waveform (c) Noise measurement waveform (d) Tone measurement waveform. 


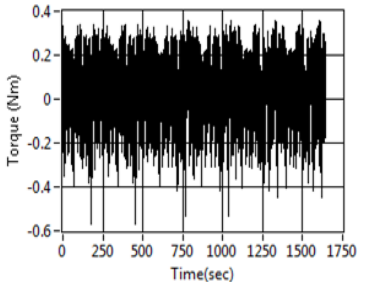

(a)

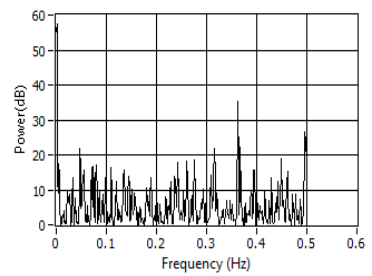

(c)

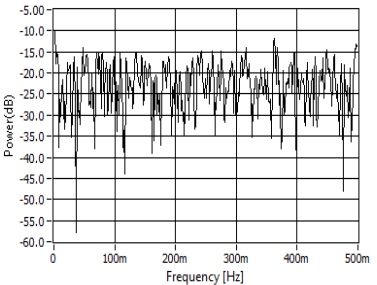

(b)

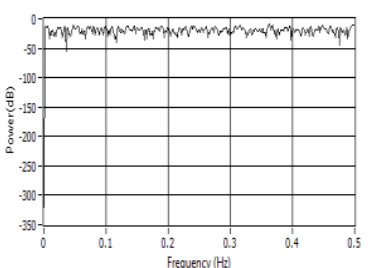

(d)
Fig- 10: Measured waveform for vibration and noise for DTC fed PMSM at a speed of $1000 \mathrm{rpm}$ at $3 \mathrm{Nm}$ load condition (a) Torque response waveform (b) Power spectrum waveform (c)

Noise measurement waveform (d) Tone measurement waveform.

In frequency domain measurement, the analyze of total noise level, average noise level, SINAD and SNR level can be measured for given input. And the main advantage of using frequency domain measurement has been analyzed the accurate noise level over a frequency ranges using the power spectrum graph. While using power spectrum, visualize see the real world signal in frequency domain measurement. From the analyzed value, the low values which has been measured at a speed of $200 \mathrm{rpm}$ for load of $2 \mathrm{Nm}$ has $0.2725 \mathrm{~dB}$ of average noise level and $0.0371 \mathrm{~dB}$ of total noise level and SINAD and SNR has a $2.33769 \mathrm{~dB}$ and $-2.9023 \mathrm{~dB}$ at a speed of 1000 $\mathrm{rpm}$. These vibration analyses are useful for evaluating the current machine condition and diagnosing the fault associated with the operational machine.

\section{IMPLEMENTATION}

A DSP based development platform is used to implement and validate the PMSM DTC schemes. The Fig- 11. Shows the overall experimental setup for investigating the mechanical vibration and acoustic noise in PMSM. The Table IV list the specification of the prototype.

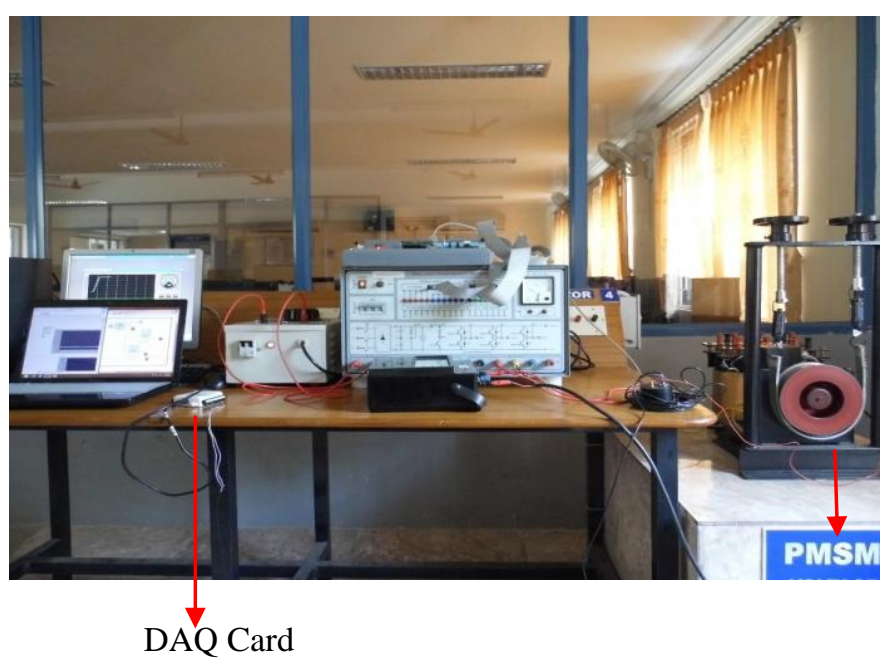

Fig- 11: Experimental setup

Table- 4: Specification of the tested PMSM

\begin{tabular}{|l|l|}
\hline MOTOR TYPE & PMSM \\
\hline RATED CURRENT & $3.25 \mathrm{~A}$ \\
\hline RATED VOLTAGE & $380 \mathrm{~V}$ \\
\hline $\begin{array}{l}\text { RATED CAPACITY OF A } \\
\text { MOTOR }\end{array}$ & $1 \mathrm{HP}$ \\
\hline RATED TORQUE & $2.9 \mathrm{Nm}$ \\
\hline RATED SPEED & $3000 \mathrm{rpm}$ \\
\hline No. of POLES & 2 poles \\
\hline TYPE OF SENSOR & ACCELEROMETER \\
& SENSOR(PG114MO) \\
\hline CHARGE CONVERTER & CC201A0 \\
\hline
\end{tabular}

The fundamental frequency can be determined from the following equation:

$$
\mathrm{f}_{\mathrm{ct} 1}=\mathrm{n} * \mathrm{~N}_{\mathrm{c}} / 60
$$

Where $\mathrm{n}$ is the rotor speed in revolution per minute and $\mathrm{N}_{\mathrm{c}}$ is the LCM between the slot and pole numbers.

The vibration response of an electrical machine is usually measured with an accelerometer mounted on the machine housing. However, the measurement of vibration response is not as straightforward as that of radial vibration. Since a standard single axis integrated circuit piezoelectric accelerometer PG114MO is used perform the measurement, it is placed circumferentially on the motor body is shown in Fig12. to ensure that the measured vibration response is mainly 
attributed to the circumferential components of the mechanical vibration. Alternatively, a more expensive three axis accelerometer may be employed to simplify the mounting.

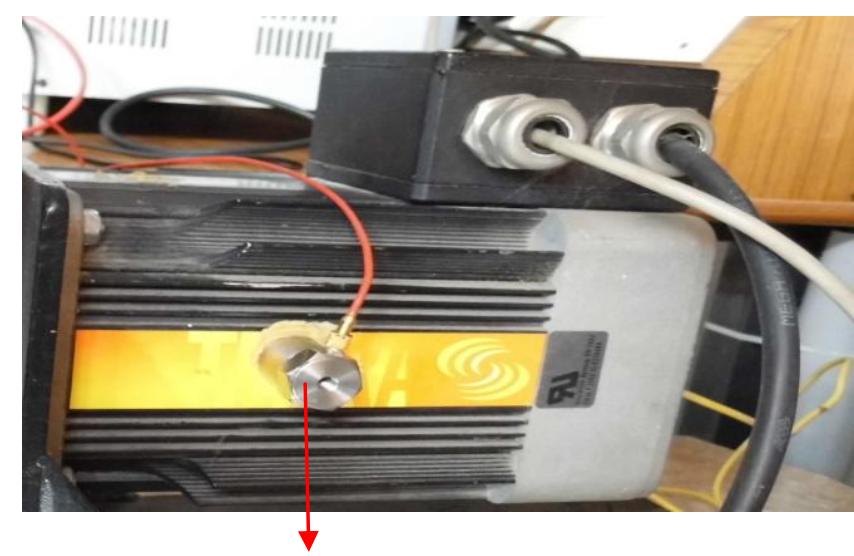

Accelerometer

Fig- 12: Schematic diagram showing the mounting of a single axis accelerometer for stator torsional vibration measurement.

\section{EXPERIMENTAL RESULTS AND DISCUSSION}

The experimental results of mechanical vibration and acoustic noise for conventional excitation was investigated for various speed and load changes. The mechanical vibration and noise can be analyzed in three axis like vertical, horizontal and axial i.e., $\mathrm{X}, \mathrm{Y}$ and $\mathrm{Z}$ axis respectively.

\subsection{Vertical Axis}

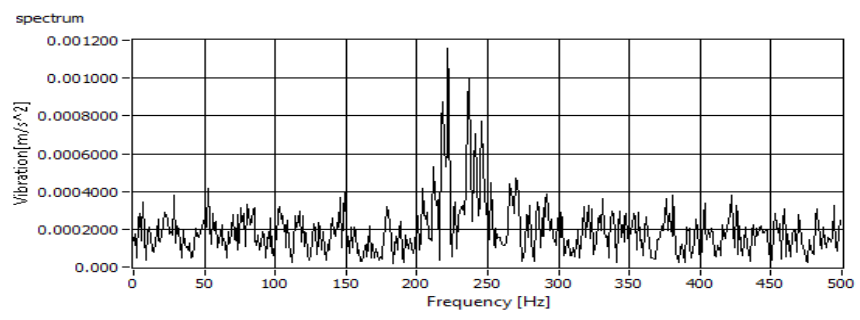

Fig- 13: Measured mechanical vibration acceleration spectra under no load condition

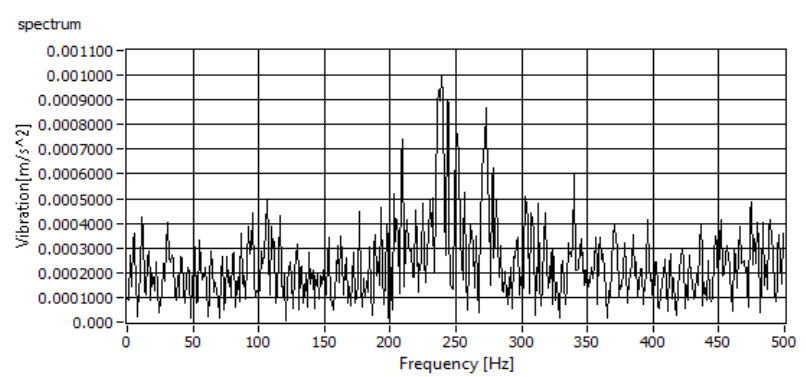

(a)

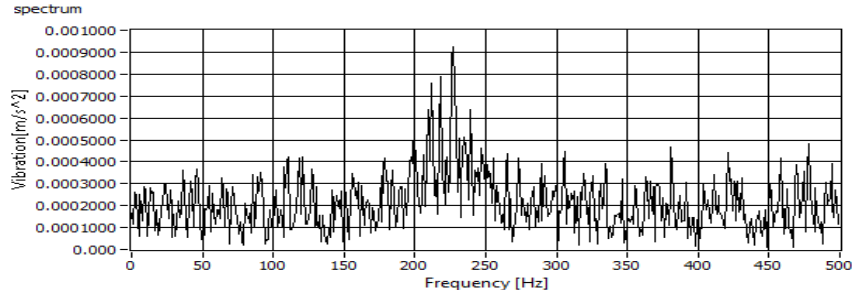

(b)

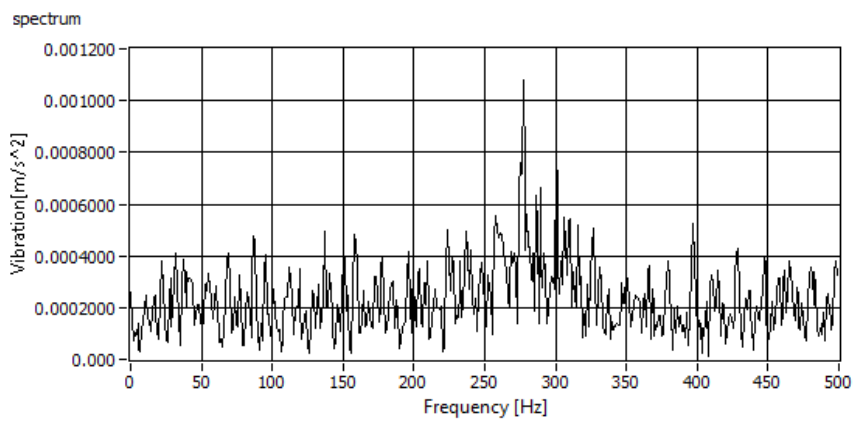

(c)

Fig- 14: Measured mechanical vibration acceleration spectra under different load conditions (a) $1 \mathrm{Nm}$ (b) $2 \mathrm{Nm}$ (c) $2.9 \mathrm{Nm}$

In vertical axis i.e., $\mathrm{X}$ axis the vibration is high as compared to the other axis acceleration spectra because of placing the accelerometer as near as possible to the centerline of the bearings. And as per the fundamental frequency the nature vibration is high for vertical spectra for both no load and load conditions. For different speed and load changes the vibration peak was altered and denoting the nature of vibration in the spectrum waveform. The maximum vibration peak is occurred between 200 to $250 \mathrm{~Hz}$.

\subsection{Axial Axis}

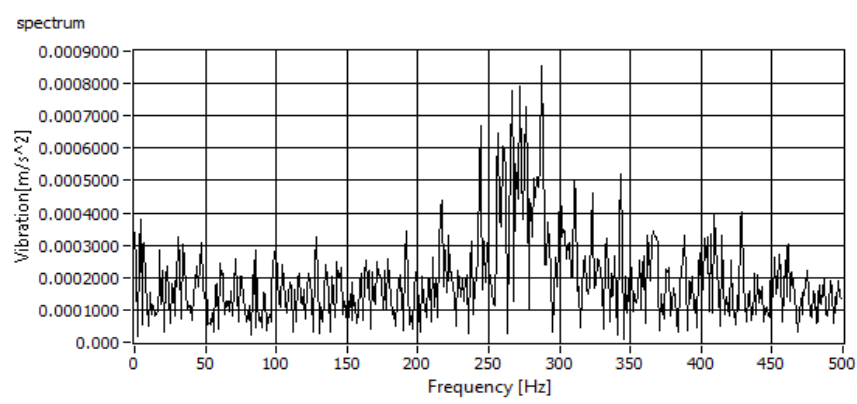

Fig- 15: Measured mechanical vibration acceleration spectra under no load condition 


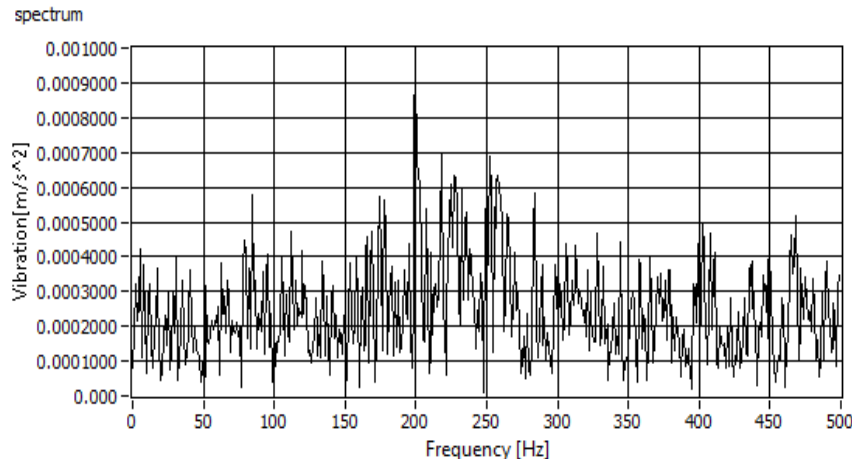

(a)

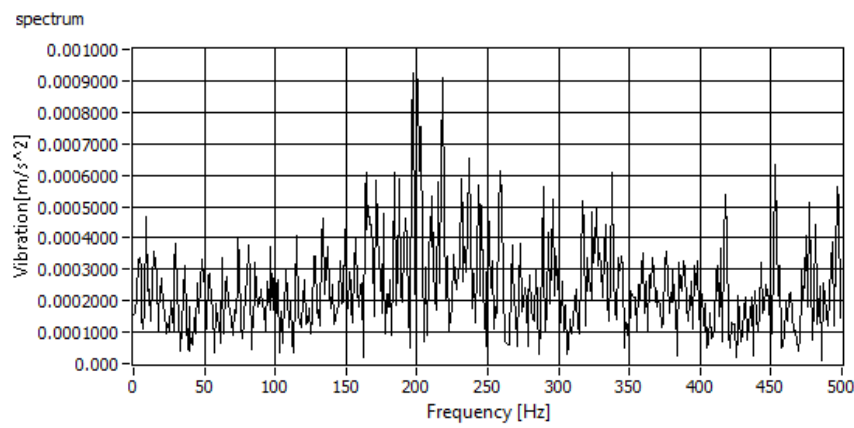

(b)

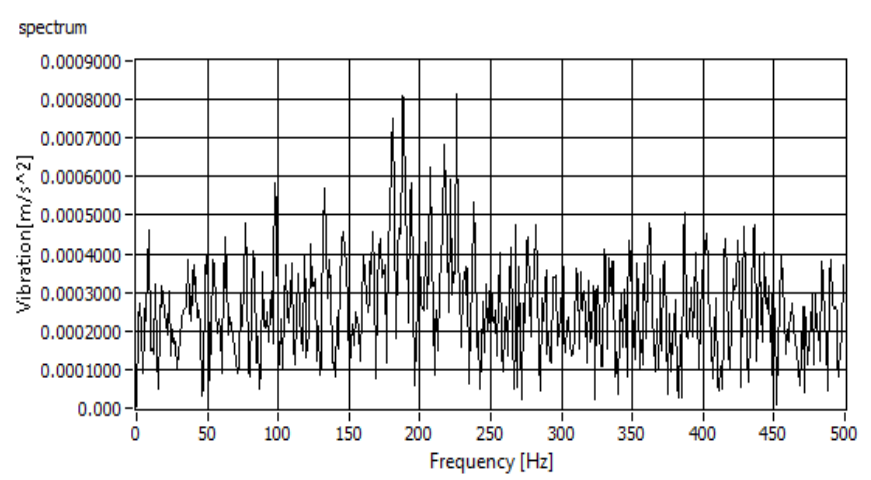

(c)

Fig- 16: Measured mechanical vibration acceleration spectra under different load conditions (a) $1 \mathrm{Nm}$ (b) $2 \mathrm{Nm}$ (c) $2.9 \mathrm{Nm}$

In axial axis i.e., $\mathrm{Y}$ axis the vibration is occurred because of any parallel misalignment in a machine. As compared to vertical axis, the axial has less vibration peak spectra as per vibration spectra for different load and speed changes. The maximum peak of vibration was occurred between $150 \mathrm{~Hz}$ to $200 \mathrm{~Hz}$ respectively.

\subsection{Horizontal Axis}

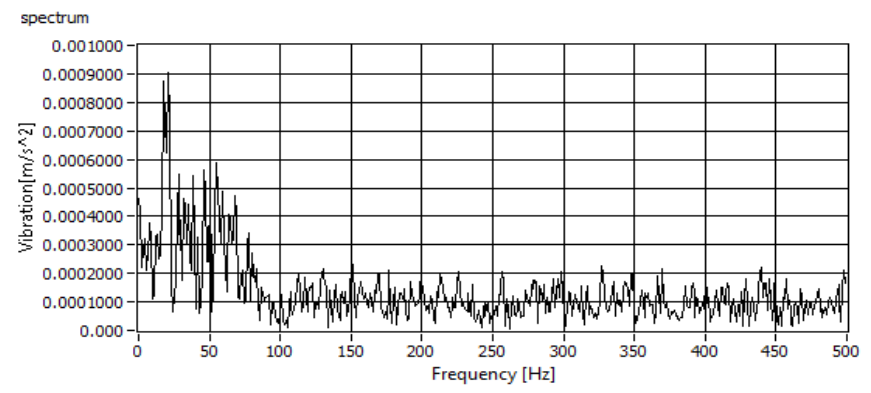

Fig- 17: Measured mechanical vibration acceleration spectra under no load condition

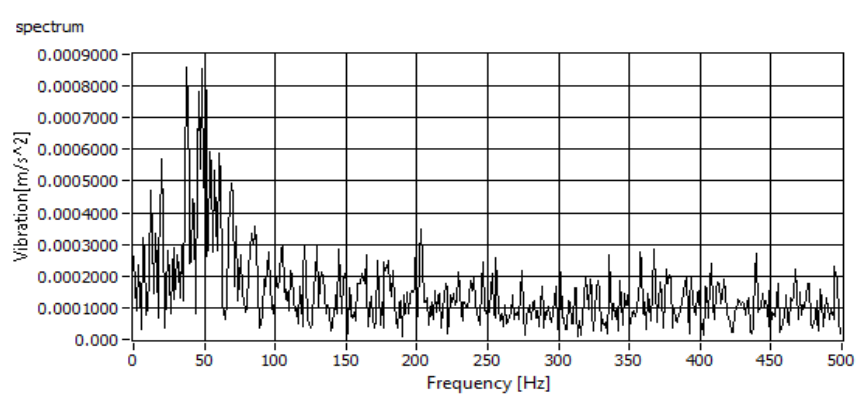

(a)

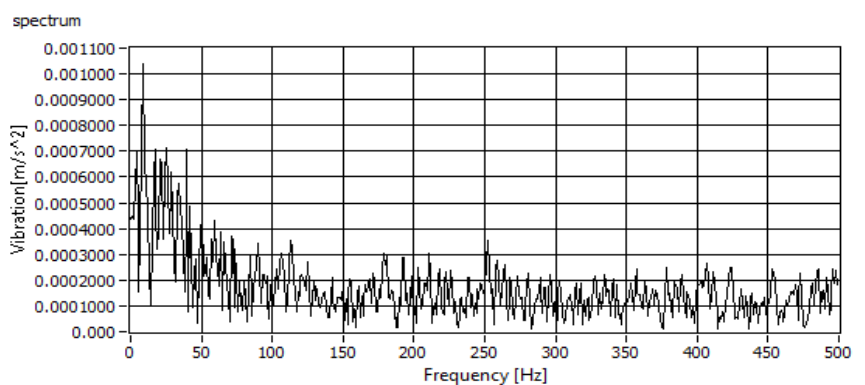

(b)

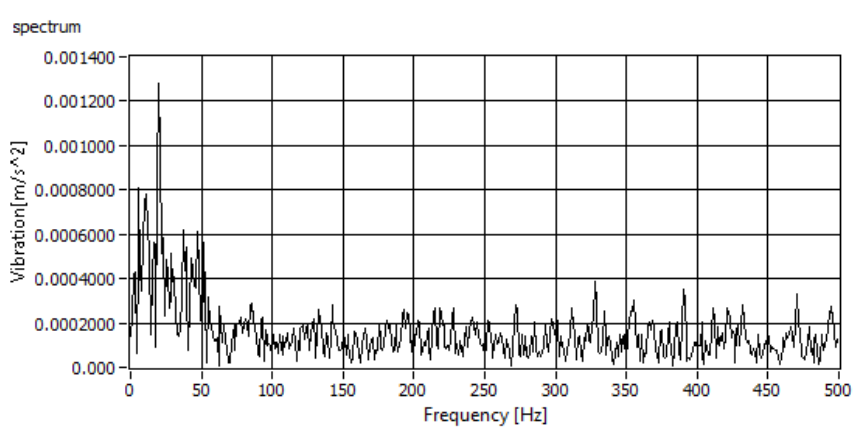

(c)

Fig-18: Measured mechanical vibration acceleration spectra under different load conditions (a) $1 \mathrm{Nm}$ (b) $2 \mathrm{Nm}$ (c) $2.9 \mathrm{Nm}$ 
In horizontal axis i.e., $\mathrm{Z}$ axis the vibration is occurred because of any angular misalignment in a machine. As compared to vertical axis and axial has very less vibration peak spectra as per vibration spectra for different load and speed changes. In these axis, it had only fundamental peak. So in this axis, there no parallel misalignment like bending moment.

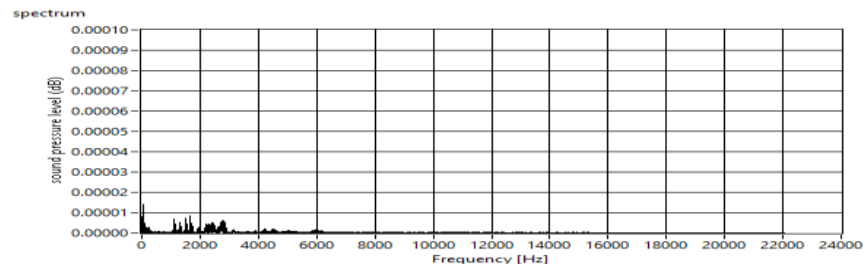

(a)

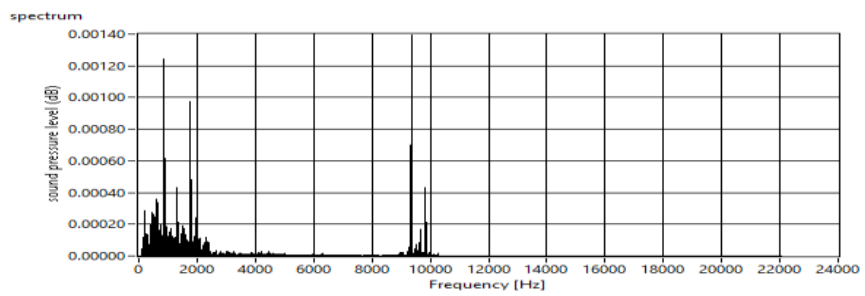

(b)

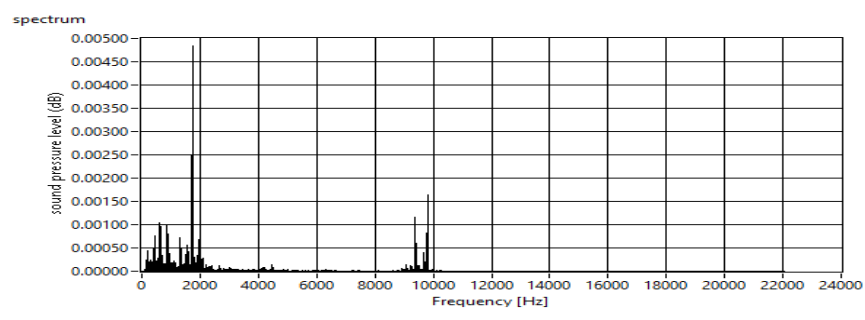

(c)

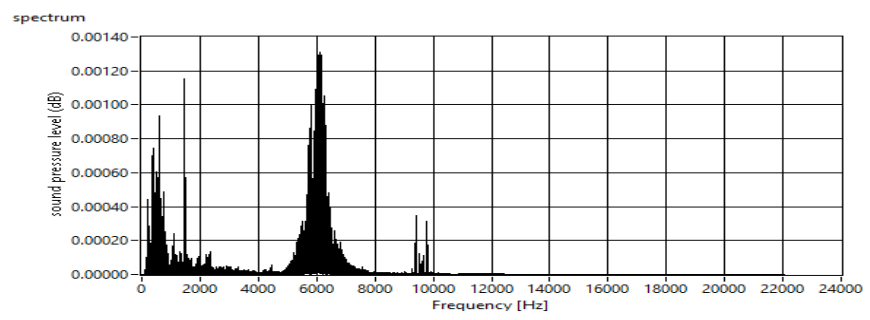

(d)

Fig- 19: Measured sound pressure level spectra under different load conditions (a) $0 \mathrm{Nm}$ (b) $1 \mathrm{Nm}$ (c) $2 \mathrm{Nm}$ (d) $2.9 \mathrm{Nm}$

In sound pressure level to be high for load condition for 2.9 $\mathrm{Nm}$ that is for rated torque. At a torque of $2.9 \mathrm{Nm}$ the sound to be high at frequency of $6000 \mathrm{~Hz}$ During no load conditions there is high noise peak occurred in a machine. When the load of machine changes the speed to be got higher frequency range

\section{CONCLUSIONS}

In this work, the mechanical vibration and acoustic noise in Direct Torque Controlled PMSM has been analyzed in terms of time domain measurement and frequency domain measurement. In time domain analysis, the Root mean Square (RMS) and Signal in Noise and Distortion (SINAD) has calculated for various speed and load changes. The mechanical vibration and acoustic noise had been analyzed for various speeds of $200 \mathrm{rpm}, 500 \mathrm{rpm}, 700 \mathrm{rpm}, 1000 \mathrm{rpm}$ for load of 2 $\mathrm{Nm}, 3 \mathrm{Nm}$ and no load condition. And in the frequency domain analysis, the vibration signal and noise is performed and the regions are detected by this analysis for various speeds and load changes. In the power spectrum analysis of frequency domain measurement, it has mentioned clearly about the average noise level, total noise level of a signal and also, the tone measurement which quantifies the linearity of the audio signal.

For time domain measurement, the analyzed mechanical vibration and acoustic noise value for $3 \mathrm{Nm}$ at a speed of 700 rpm has a low SINAD and RMS of $0.1784 \mathrm{~dB}$ and 0.1994 $\mathrm{mm} / \mathrm{sec}$ and for $2 \mathrm{Nm}$ at a speed of $500 \mathrm{rpm}$ has a low RMS and SINAD of $0.1942 \mathrm{~mm} / \mathrm{Sec}$ and $0.9136 \mathrm{~dB}$. For frequency domain measurement, the analyzed average noise level and total noise level for loaded and no load conditions. At no load condition the low value which analyzed at a speed of 1000 RPM of $0.0366 \mathrm{~dB}$ and $0.2706 \mathrm{~dB}$. For experimental setup, the analysis for conventional excitation has high vibration peak spectrum for vertical axis. As compared to axial and horizontal axis the vertical axis had high vibration peak. The result obtained from the analyses of both time domain and frequency domain was done by Lab VIEW. With this development of graphical language it gives high performance, flexibility and accurate information about the signal.

\section{REFERENCES}

[1] J. W. Ahn, S. J. Park, and D. H. Lee (2004), "Hybrid excitation of SRM for reduction of vibration and acoustic noise," IEEE Trans. Ind. Electron., vol. 51, no. 2

[2] Dirk Braunisch, Bernd Ponick and Gerd Bramerdorfer (2013)," Combined Analytical-Numerical Noise Calculation of Electrical Machines Considering Nonsinusoidal Mode Shapes", IEEE transactions on magnetics, vol. 49, no.4

[3] Dimitri Torregrossa, Amir Khoobroo, and Babak Fahimi(2012), "prediction of acoustic noise and torque pulsation in pm synchronous machines with static eccentricity and partial demagnetization using field reconstruction method", IEEE transactions on industrial electronics, vol. 59, no. 2.

[4] S. A. Long, Z. Q. Zhu, and D. Howe (2001), "Vibration behavior of stators of switched reluctance motors," Proc. Inst. Elect. Eng., Electr. Power Appli., vol. 148, no. 3 . 
[5] Lakshmikanth S, Natraj K.R, Rekha K.R (2012), "Noise and vibration reduction in permanent magnet synchronous motor- a review", International Journal of Electrical and Computer Engineering Vol.2, no.3.

[6] Rakib Islam and Iqbal Husain (2010), "Analytical model for predicting noise and vibration in permanentmagnet synchronous motors", IEEE Transactions on industry applications, vol. 46, no. 6

[7] D. Y. Kim, G. H. Jang, J. K. Nam(2013), “magnetically induced vibrations in an IPM motor due to distorted magnetic forces arising from flux weakening control", IEEE transactions on magnetics, vol. 49, no. 7.

[8] Sunita Mohanta, Umesh Chandra Pati (2011),"monitoring and analysis of vibration signal based on virtual instrumentation", international journal of advanced computer research (ISSN) volume

[9] Sunghyuk park, Sungil kim, Wonho kim, Jinwoo cho, Seong taelim(2012), "A numerical model for predicting vibration and Acoustic noise of IPMSM", IEEE Vehicle Power and Propulsion Conference.

[10]. J.H.Leong, Z.Q. Zhu (2011), "Acoustic noise and vibration of direct torque controlled permanent magnet brushless DC drives", IEEE International Conference.

[11] Rakib islam, Member, IEEE, Iqbal husain, Fellow(2009), IEEE," Analytical Model for Predicting Noise and Vibration in Permanent Magnet Synchronous Motors", IEEE International conference.

[12] D. E. Cameron, J. H. Lang, and S. D. Umans(1992), "The origin and reduction of acoustic noise in doubly salient variable reluctance motor," IEEE Trans. Ind. Appl., vol. 26, no.5

[13] R. S. Colby, F. M. Mottier, and T. J. E. Miller (1996), "Vibration modes and acoustic noise in a four-phase switched reluctance motor," IEEE Trans.Ind Appl., vol. 32, no. 6

[14] W. Cai, P. Pillay, and Z. Tang (2002), "Impact of stator windings and end-bells on resonant frequencies and mode shapes of switched reluctance motors," IEEE Trans. Ind. Appl., vol. 38, no. 4.

[15] M. Gabsi, F. Camus, T. Loyau, and J. L. Barbry (1999), "Noise reduction of switched reluctance motor," in Proc. IEEE Int. Elect Mach. Drives Conference

[16] Jui-Yuan Chai, Yeh-Hsiang Ho, Yu-Choung Chang and Chang-Ming Liaw(2008), "On acoustic-noisereduction control using random switching technique for switch-mode rectifiers in pmsm drive", IEEE transactions on industrial electronics, vol. 55, no 3.

[17] C. Pollock and C. Y. Wu(1997), "Acoustic noise cancellation techniques for switched reluctance drive," IEEE Trans. Ind. Appl., vol. 33, no. 2.

[18] J. B. Sun, Q. H. Zhan, S. H. Wang, and Z. Y. $\mathrm{Ma}(2007)$, "A novel radiating rib structure in switched reluctance motors for low acoustic noise," IEEE Trans. Magn., vol. 43, no. 9.

[19] K. N. Srinivas and R. Arumugam (2004), "Static and dynamic vibration analyses of switched reluctance motors including bearings, housing, rotor dynamics, and applied loads," IEEE Trans.Magn., vol. 40, no. 4.

[20] Y. Tang (1997), "Characterization, numerical analysis, and design of switched reluctance motors," IEEE Trans. Ind. Appl., vol. 33, no. 6.

[21] C.Y.Wu and C. Pollock(1995), "Analysis and reduction of vibration and acoustic noise in the switched reluctance drive," IEEE Trans. Ind. Appl., vol. 31, no. 1.

[22] C. Y.Wu and C. Pollock (2008), "Time domain analysis of vibration and acoustic noise in the switched reluctance drive," in Proc. Int. Conference Electr Mach.Drives

[23] Z. Q. Zhu, Fellow, IEEE, X. Liu, And Zaiping Pan (2011), "Analytical Model for Predicting Maximum Reduction Levels Machine by Active Vibration Cancellation", IEEE Transactions on Energy Conversion, Vol. 26, no. 1

\section{BIOGRAPHIE}

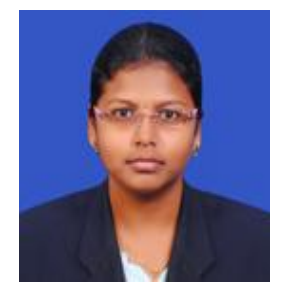

R.Sathya completed her B.E. degree in MPNMJ Engineering College, Chennimalai (Anna university, Chennai) in 2012. Now, she pursuing her M.E. degree in Kongu Engineering College, Perundurai. Her area of interest includes power electronics and electric drives. 